\title{
Effect of texture microstructure on tribological properties of tailored $\mathrm{Ti}_{3} \mathrm{AlC}_{2}$ ceramic
}

\author{
Ludi XU ${ }^{a}$, Degui ZHU ${ }^{a}$, Salvatore GRASSO ${ }^{b}$, Tohru S. SUZUKI ${ }^{c}$, \\ Akira KASAHARA ${ }^{c}$, Masahiro TOSA ${ }^{c}$, Byung-nam $\mathrm{KIM}^{c}$, Yoshio SAKKA ${ }^{c}$, \\ Minhao $\mathrm{ZHU}^{a}$, Chunfeng $\mathrm{HU}^{a,{ }^{*}}$ \\ ${ }^{a}$ Key Laboratory of Advanced Technologies of Materials, Ministry of Education, School of Materials Science \\ and Engineering, Southwest Jiaotong University, Chengdu 610031, China \\ ${ }^{b}$ School of Engineering and Material Science, Queen Mary University of London, London E1 4NS, UK \\ ${ }^{c}$ National Institute for Materials Science, Tsukuba, Ibaraki 305-0047, Japan
}

Received: January 08, 2017; Revised: March 14, 2017; Accepted: March 17, 2017

(C) The Author(s) 2017. This article is published with open access at Springerlink.com

\begin{abstract}
Tribological property of $c$-axis textured shell-like $\mathrm{Ti}_{3} \mathrm{AlC}_{2}$ ceramic was investigated using reciprocating sliding balls (SUS304) under loads of 1, 5, and $9 \mathrm{~N}$. It was found that the textured top surface (TTS), corresponding to the $(000 l)$ plane, shows the lowest mean coefficient of friction in comparison with those measured on the textured side surface (TSS), where the sliding directions are parallel (TSS-1) and perpendicular (TSS-2) to $c$ axis, under the same load. Among all the tested orientations, the TSS-2 exhibited the lowest wear rate of $1.51 \times 10^{-3} \mathrm{~mm}^{3} /(\mathrm{N} \cdot \mathrm{m})$ under the load of $9 \mathrm{~N}$. The worn mechanisms on the TTS and TSS-1 were delamination, grain fracture, and grain spalling-off. On the TSS-2, plowing effect against balls was the dominating mechanism. This work suggests the criteria to maximize the wear resistance in the load range of 1-9 N.
\end{abstract}

Keywords: tailored $\mathrm{Ti}_{3} \mathrm{AlC}_{2}$; mean coefficient of friction; wear rate; worn mechanisms

\section{Introduction}

Ternary compounds $\mathrm{M}_{n+1} \mathrm{AX}_{n}$ phases ( $\mathrm{M}$ is the transition metal, $\mathrm{A}$ is the A group element, $\mathrm{X}$ is $\mathrm{C}$ or $\mathrm{N}$, and generally $n=1-3$ ) belong to a large family with nanolaminar microstructure and hexagonal crystal structure (space group P63/mmc) [1-5]. To date, more than fifty 211 phases, five 312 phases, and eight 413 phases (excluding solid solutions) have been discovered. Recently, it has been confirmed that 514, 615, and 716 phases also exist [6-8]. Therefore, $n$ values could be extended to 4,5 , and 6 . Interestingly, a

* Corresponding author.

E-mail: chfhu@live.cn new nanolayered 221 phase, $\mathrm{Mo}_{2} \mathrm{Ga}_{2} \mathrm{C}$, has been recently synthesized by solid/liquid reaction and magnetron sputtering [9]. It is a new type of MAX phase not belonging to the formula $\mathrm{M}_{n+1} \mathrm{AX}_{n}$, and more 221 phases might be discovered in the following years.

Since 1996, it has been demonstrated that some of MAX phases, such as $\mathrm{Ti}_{3} \mathrm{SiC}_{2}, \mathrm{Ti}_{3} \mathrm{AlC}_{2}, \mathrm{Ti}_{2} \mathrm{AlC}$, $\mathrm{Cr}_{2} \mathrm{AlC}$, etc., possess an unique combination of high Young's modulus, high flexural strength, high fracture toughness, excellent thermal shock resistance, and oxidation resistance [10-13]. Notably, it was found that these phases offer an excellent corrosion resistance against molten $\mathrm{Pb}$ above $850{ }^{\circ} \mathrm{C}$ together with good irradiation resistance to neutron and $\mathrm{Kr}, \mathrm{Xe}, \mathrm{Au}$ ions [14-16]. Therefore, they could be good candidates for 
use in the fourth generation nuclear plants.

As for advanced structural materials, tribological properties of MAX phases are very important. Gupta et al. [17] systemically investigated the tribological behaviors of $\mathrm{Ti}_{2} \mathrm{AlC}, \mathrm{Cr}_{2} \mathrm{AlC}, \mathrm{Ta}_{2} \mathrm{AlC}, \mathrm{Ti}_{3} \mathrm{SiC}_{2}, \mathrm{Ti}_{2} \mathrm{AlN}$, $\mathrm{Ti}_{4} \mathrm{AlN}_{3}, \mathrm{Cr}_{2} \mathrm{GeC}, \mathrm{Cr}_{2} \mathrm{GaC}, \mathrm{Nb}_{2} \mathrm{SnC}$, and $\mathrm{Ti}_{2} \mathrm{SnC}$, tested against Ni-based superalloys at ambient and high temperatures $\left(550{ }^{\circ} \mathrm{C}\right)$. It was determined that at room temperature the wear rates are relatively high $(\geqslant$ $\left.10^{-4} \mathrm{~mm}^{3} /(\mathrm{N} \cdot \mathrm{m})\right)$ due to abrasion against the third body. At $550{ }^{\circ} \mathrm{C}$, oxidized transfer films formed on both contacting surfaces, and their lubricant function contributed to a reduced wear rate $\left(<10^{-6} \mathrm{~mm}^{3} /(\mathrm{N} \cdot \mathrm{m})\right)$ [17]. Also, they found that if the counterpart is alumina against $\mathrm{Ta}_{2} \mathrm{AlC}, \mathrm{Ti}_{2} \mathrm{AlC}, \mathrm{Cr}_{2} \mathrm{AlC}$, and $\mathrm{Ti}_{3} \mathrm{SiC}_{2}$, even when tested under dry sliding conditions at $550{ }^{\circ} \mathrm{C}$, no visible wear track is observed and tribofilms are mainly constituted of amorphous oxides of $\mathrm{M}$ and $\mathrm{A}$ elements [18].

In wet and aggressive conditions (hydrochloric acid, alkalis, water, and ethanol), the tribo-corrosion behaviors of $\mathrm{Ti}_{3} \mathrm{SiC}_{2} / \mathrm{Si}_{3} \mathrm{~N}_{4}$ countercouple were investigated. Even if the formation of $\mathrm{SiO}_{2}$ film decreased the coefficient of friction (COF), this was not effective to prevent grains detaching from the bulk. In $\mathrm{Ti}_{3} \mathrm{SiC}_{2}$, mechanical damage dominated the wear behavior rather than the chemical corrosion $[19,20]$.

Zhu et al. [21] systematically investigated the dry sliding tribological behaviors of $\mathrm{Ti}_{3} \mathrm{SiC}_{2}$ at room temperature in air, coupled with different counterfaces, including $\mathrm{Ti}_{3} \mathrm{SiC}_{2}, \mathrm{Al}_{2} \mathrm{O}_{3}, \mathrm{Si}_{3} \mathrm{~N}_{4}, \mathrm{SiC}$, and $\mathrm{GCr} 15$ bearing-steel. The highest wear rate $\left(1.87 \times 10^{-3}\right.$ $\mathrm{mm}^{3} /(\mathrm{N} \cdot \mathrm{m})$ ) was observed in the $\mathrm{Ti}_{3} \mathrm{SiC}_{2} / \mathrm{Ti}_{3} \mathrm{SiC}_{2}$ friction pair. However, the lowest wear rate $\left(2.09 \times 10^{-4}\right.$ $\mathrm{mm}^{3} /(\mathrm{N} \cdot \mathrm{m})$ ) was obtained in the $\mathrm{Ti}_{3} \mathrm{SiC}_{2} / \mathrm{SiC}$ friction pair. They found that oxide films protect the surface of $\mathrm{Ti}_{3} \mathrm{SiC}_{2} / \mathrm{SiC}$ friction pair from direct contact and decrease wear rate [21].

In order to enhance the wear resistance, Wan et al. [22] fabricated the $\mathrm{SiC}$ reinforced $\mathrm{Ti}_{3} \mathrm{Si}(\mathrm{Al}) \mathrm{C}_{2}$ composites (10-30 vol\%) and tested against AISI52100 steel balls at room temperature. They found that with increasing $\mathrm{SiC}$ content, both the coefficient of friction and wear rate are significantly decreased. The enhanced wear resistance was mainly ascribed to the pinning effect of $\mathrm{SiC}$ particles by inhibiting the plastic deformation and fracture of softer matrix, and to the lubricating effect of oxide debris [22]. Similar behavior was confirmed for $\mathrm{Al}_{2} \mathrm{O}_{3}$-reinforced $\mathrm{Ti}_{3} \mathrm{SiC}_{2}$ composites $\left(10\right.$ and $\left.20 \mathrm{vol} \% \quad \mathrm{Al}_{2} \mathrm{O}_{3}\right)$ against AISI-52100 steel balls tested in dry air in reciprocating mode. It was determined that the hard $\mathrm{Al}_{2} \mathrm{O}_{3}$ particles pin the surrounding soft matrix and delocalize the shear stresses, so, reducing the wear rate [23].

The previous reports were exclusively focused on isotropic MAX phases. However, because of their layered nature, it is expected that their wear behavior is strongly dependent on the crystallographic orientation. Recently, $\mathrm{Hu}$ et al. [24-27] fabricated the $c$-axis textured $\mathrm{Nb}_{4} \mathrm{AlC}_{3}, \mathrm{Ti}_{3} \mathrm{SiC}_{2}$, and $\mathrm{Ti}_{3} \mathrm{AlC}_{2}$ using the strong magnetic field alignment (SMFA) method followed by spark plasma sintering, and the resulting materials showed a shell-like mechanical behavior. These textured ceramics possessed marked anisotropic physical properties and outstanding mechanical response. For example, the tailored $\mathrm{Nb}_{4} \mathrm{AlC}_{3}$ ceramic showed the high flexural strength above $1200 \mathrm{MPa}$ and high fracture toughness above $18 \mathrm{MPa} \cdot \mathrm{m}^{1 / 2}$ parallel to the $c$-axis direction [28]. The latter suggests that textured MAX phases might exhibit excellent wear resistance.

In the present work, the mean coefficient of friction and wear rate of textured $\mathrm{Ti}_{3} \mathrm{AlC}_{2}$ ceramic are investigated by characterizing the different texture directions against SUS304 balls at room temperature. The worn mechanisms on the different texture surfaces will be discussed.

\section{Experimental procedure}

The textured $\mathrm{Ti}_{3} \mathrm{AlC}_{2}$ ceramic was fabricated by strong magnetic field alignment method followed by spark plasma sintering as detailed in Ref. [27]. The density of textured $\mathrm{Ti}_{3} \mathrm{AlC}_{2}$ was $4.21 \mathrm{~g} / \mathrm{cm}^{3}$. The measured Vickers hardness on the TTS (7.4 GPa) was about $28 \%$ higher than that on the TSS $(5.8 \mathrm{GPa})$. Samples for wear testing were machined by electrical discharge cutting. The samples with a dimension of $2 \mathrm{~mm} \times 4 \mathrm{~mm} \times$ $10 \mathrm{~mm}$ were employed; for each of them the $4 \mathrm{~mm} \times$ $10 \mathrm{~mm}$ side was polished down to $0.5 \mu \mathrm{m}$ diamond grids, resulting in a surface roughness of $20 \mathrm{~nm}$. Figure 1 presents the schematic relationship between sliding direction of balls and texture surface of tailored $\mathrm{Ti}_{3} \mathrm{AlC}_{2}$. According to the anisotropic microstructure of textured $\mathrm{Ti}_{3} \mathrm{AlC}_{2}$ ceramic, the tested planes were named as textured top surface (TTS) and textured side surface (TSS-1 and TSS-2), as shown in Figs. 1(a)-1(c), respectively.

The reciprocating tribological testing was conducted by using an HEIDON facility (SHINTO Scientific Co., 
(a) TTS

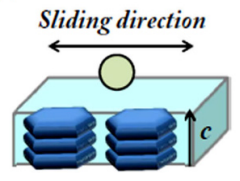

(b) TSS-1
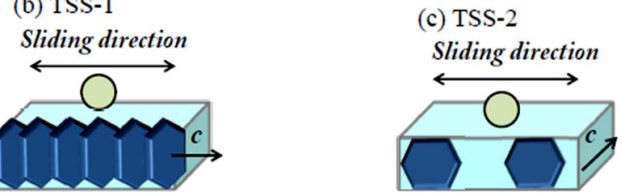

Fig. 1 Schematic figures of wear test along the different texture directions: (a) on the textured top surface (TTS), (b) on the textured side surface (parallel to $c$ axis) (TSS-1), and (c) on the textured side surface (perpendicular to $c$ axis) (TSS-2).

Ltd., Tokyo, Japan) with 500 times of cycling. The sliding distance of counterpair SUS304 balls with a diameter of $3 \mathrm{~mm}$ was $7 \mathrm{~mm}$ and the sliding speed was $1 \mathrm{~mm} / \mathrm{s}$. The load was set as 1, 5, and $9 \mathrm{~N}$ and the load error was below $10 \mathrm{~g}$. For each load, three samples were tested along one direction (in total 27 samples were tested). The coefficient of friction was recorded in real time during the test. After testing, the collected wear debris and worn surface of samples and balls were examined by a JEOL5600 scanning electron microscope (SEM; JEOL Ltd., Tokyo, Japan) equipped with energy dispersive X-ray spectroscopy (EDS). After ultrasonic cleaning in ethanol for $30 \mathrm{~min}$ and drying in air, the worn samples were weighed by an electrical balance with a high accuracy of $0.1 \mathrm{mg}$. The wear volumes of samples were calculated based on the weight loss and density. And those of balls were calculated according to the diameter of worn surface using the spherical volume formula. Then the wear rates were calculated by an equation:

$$
W=\frac{M}{L D}
$$

in which $M$ is the wear volume, $L$ is the force, and $D$ is the sliding distance [23]. In order to determine the worn mechanisms of anisotropic $\mathrm{Ti}_{3} \mathrm{AlC}_{2}$ ceramic, the ultrasonic cleaned worn surfaces were observed by SEM. Furthermore, Vickers indentions $(50 \mathrm{~N})$ on the worn surfaces were used to characterize the anisotropic wear damage of textured $\mathrm{Ti}_{3} \mathrm{AlC}_{2}$.

\section{Results and discussion}

\section{1 Texture microstructure of tailored $\mathrm{Ti}_{3} \mathrm{AlC}_{2}$}

Figure 2 shows the X-ray diffraction (XRD) patterns
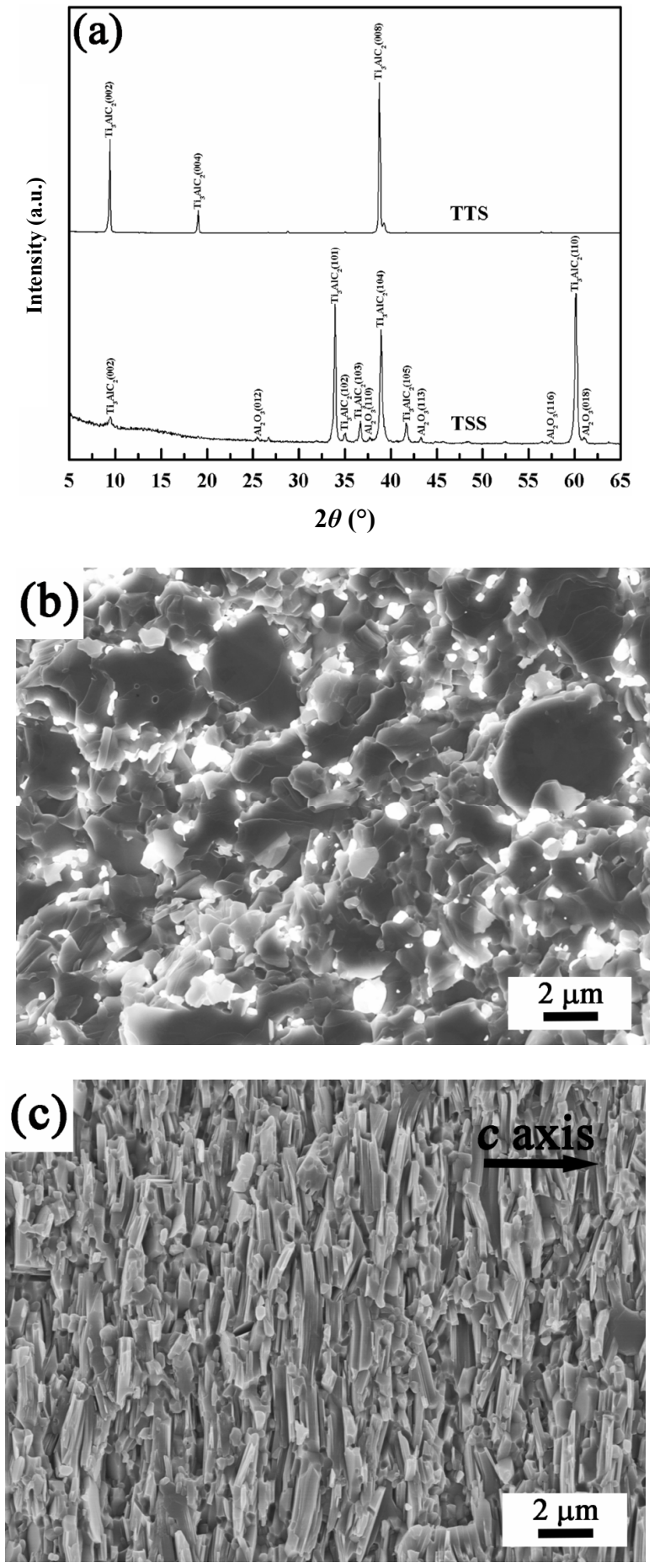

Fig. 2 (a) XRD patterns of textured top surface (TTS) and textured side surface (TSS) of tailored $\mathrm{Ti}_{3} \mathrm{AlC}_{2}$ ceramic, and SEM micrographs of fracture surfaces of (b) TTS and (c) TSS.

and texture microstructure of tailored $\mathrm{Ti}_{3} \mathrm{AlC}_{2}$ ceramic. It is observed that on the textured top surface (TTS), the typical diffraction peaks are $(000 l)$ basal plane. On the textured side surface (TSS), (101), (104), and (110) planes are corresponded to [11-20] axis direction (Fig. 
2(a)). Additionally, the fracture surfaces of TTS and TSS exhibit that plate grains stack orderly (Figs. 2(b) and 2(c)), indicating the anisotropic shell-like microstructure. Also, it is observed that $\mathrm{Al}_{2} \mathrm{O}_{3}$ particles (about 15.4 vol\%) homogeneously distribute in the $\mathrm{Ti}_{3} \mathrm{AlC}_{2}$ matrix, which might enhance the wear resistance of soft $\mathrm{Ti}_{3} \mathrm{AlC}_{2}$ matrix [27].

\section{2 Tribological behaviors}

Table 1 lists the mean coefficient of friction of textured $\mathrm{Ti}_{3} \mathrm{AlC}_{2}$ as a function of load against SUS304 balls along different texture directions. The mean coefficient of friction was averaged for the whole time duration of the test and for the three samples tested for each orientation. The samples were tested under the loads of 1,5 , and $9 \mathrm{~N}$. It is seen that the mean coefficient of friction increases in the order of TTS, TSS-1, and TSS-2 under the same load. On the TTS, the mean coefficient of friction shows a significant increase from 0.184 to 0.228 with the increment of load. The weak bondings on the basal planes between the Ti-C layers were fractured by the sliding balls on the contact surface of TTS sample [3]. Under higher load, more surface material on the contact region was scratched and removed by shearing mechanism. As a result, the sliding resistance became larger, resulting in higher mean coefficient of friction.

On the TSS-1, by increasing the load, the mean coefficient of friction increases from 0.245 to 0.250 and then decreases to 0.237 . On the TSS-2, the mean coefficient of friction is achieved with the values of $0.257(1 \mathrm{~N}), 0.289(5 \mathrm{~N})$, and $0.282(9 \mathrm{~N})$. It is suspected that on the TSS- 1 and TSS-2, the scratch resistance undoubtedly shows the positive effect on the enhancement of coefficient of friction under the loads of 1 and $5 \mathrm{~N}$. However, the reverse tendency of decrease of mean coefficient of friction under the load of $9 \mathrm{~N}$ is possibly ascribed to the formation of oxide debris which lubricated the countercouples so as to weaken the sliding resistance [29].

Tables 2 and 3 list the wear rates of textured $\mathrm{Ti}_{3} \mathrm{AlC}_{2}$ samples and SUS304 balls as a function of load, respectively. It is clearly seen that the wear loss of

Table 1 Mean coefficient of friction of tailored $\mathrm{Ti}_{3} \mathrm{AlC}_{2}$ ceramic against SUS304 balls along different texture directions

\begin{tabular}{cccc}
\hline & $1 \mathrm{~N}$ & $5 \mathrm{~N}$ & $9 \mathrm{~N}$ \\
\hline TTS & $0.184 \pm 0.007$ & $0.219 \pm 0.004$ & $0.228 \pm 0.016$ \\
TSS-1 & $0.245 \pm 0.019$ & $0.250 \pm 0.003$ & $0.237 \pm 0.014$ \\
TSS-2 & $0.257 \pm 0.005$ & $0.289 \pm 0.005$ & $0.282 \pm 0.001$ \\
\hline
\end{tabular}

Table 2 Wear rate of textured $\mathrm{Ti}_{3} \mathrm{AlC}_{2}$ ceramic tested along different directions under different loads

\begin{tabular}{cccc} 
& & & $\left(\right.$ Unit: $10^{-3} \mathrm{~mm}^{3} /(\mathrm{N} \cdot \mathrm{m})$ \\
\hline & $1 \mathrm{~N}$ & $5 \mathrm{~N}$ & $9 \mathrm{~N}$ \\
\hline TTS & $6.79 \pm 0.62$ & $2.49 \pm 1.96$ & $85.01 \pm 18.32$ \\
TSS-1 & $13.58 \pm 4.75$ & $3.62 \pm 2.07$ & $3.02 \pm 0.85$ \\
TSS-2 & $9.05 \pm 3.91$ & $4.07 \pm 1.36$ & $1.51 \pm 0.76$ \\
\hline
\end{tabular}

Table 3 Wear rate of corresponding SUS304 balls tested along different directions under different loads

\begin{tabular}{cccc} 
& & & $\left(\right.$ Unit: $10^{-5} \mathrm{~mm}^{3} /(\mathrm{N} \cdot \mathrm{m})$ \\
\hline & $1 \mathrm{~N}$ & $5 \mathrm{~N}$ & $9 \mathrm{~N}$ \\
\hline TTS & $12.67 \pm 2.49$ & $30.78 \pm 3.12$ & $272.56 \pm 46.13$ \\
TSS-1 & $2.97 \pm 0.17$ & $7.16 \pm 1.95$ & $15.81 \pm 1.54$ \\
TSS-2 & $3.13 \pm 1.14$ & $1.51 \pm 0.20$ & $1.77 \pm 0.24$ \\
\hline
\end{tabular}

textured $\mathrm{Ti}_{3} \mathrm{AlC}_{2}$ exhibits different values along different sliding directions under the same load, as shown in Table 2. On the TTS, the wear rate is as low as $6.79 \times 10^{-3} \mathrm{~mm}^{3} /(\mathrm{N} \cdot \mathrm{m})$ under the load of $1 \mathrm{~N}$. Under the same load, the wear rates on the TSS- 1 and TSS- 2 are $13.58 \times 10^{-3}$ and $9.05 \times 10^{-3} \mathrm{~mm}^{3} /(\mathrm{N} \cdot \mathrm{m})$, respectively. This suggests that the self-lubricant mechanism of $\mathrm{Ti}_{3} \mathrm{AlC}_{2}$ is comparable to the one occurring in graphite [30,31]. Therefore, considering the preferential nanolaminar microstructure of $\mathrm{Ti}_{3} \mathrm{AlC}_{2}$ grains, the lowest wear rate on the TTS is possibly ascribed to its self-lubricating behavior. When increasing the loads up to 5 and $9 \mathrm{~N}$, the wear rate on the TTS exhibits an initial decrease to $2.49 \times 10^{-3} \mathrm{~mm}^{3} /(\mathrm{N} \cdot \mathrm{m})$ and then increases greatly to $85.01 \times 10^{-3} \mathrm{~mm}^{3} /(\mathrm{N} \cdot \mathrm{m})$. It is suggested that under the load of $5 \mathrm{~N}$ self-lubricity still contributes positively to wear rate. However, under the load of $9 \mathrm{~N}$ the material is prone to be removed quickly due to the weak bonding of basal planes.

Interestingly, for the specimens of TSS-1 and TSS-2, the wear rates show a continuous decrease with increasing load. For TSS-1 sample, the wear rates are $3.62 \times 10^{-3}$ and $3.02 \times 10^{-3} \mathrm{~mm}^{3} /(\mathrm{N} \cdot \mathrm{m})$ respectively under the loads of 5 and $9 \mathrm{~N}$. And for TSS-2, those are $4.07 \times 10^{-3}$ and $1.51 \times 10^{-3} \mathrm{~mm}^{3} /(\mathrm{N} \cdot \mathrm{m})$ respectively. The reason for this is the existence of oxide debris on the wear tracks, such as $\mathrm{Ti}-\mathrm{O}, \mathrm{Al}-\mathrm{O}, \mathrm{Fe}-\mathrm{O}$, or $\mathrm{Cr}-\mathrm{O}$ particles [32]. Even if the third body abrasion occurred during the testing, these oxide debris probably plays an important role on lubricating the counterpairs to weaken the scratching effect. Additionally, Barsoum et al. [33] found that $\mathrm{Ti}_{3} \mathrm{SiC}_{2}$ ceramic shows a fully strain reversible deformation when being compressed up to $1 \mathrm{GPa}$; after removing the load, $25 \%$ of the mechanical energy is dissipated. Such dissipation is attributed to the reversible formation and annihilation of incipient 
kink bands when deforming at room temperature. Similarly, Jones et al. [34] investigated the reversible hysteresis of single $\mathrm{Ti}_{3} \mathrm{SiC}_{2}$ crystal by nano indentation and confirmed that it is associated with conventional dislocation flow. Owing to the similar crystal structure of $\mathrm{Ti}_{3} \mathrm{AlC}_{2}$, especially the grains' basal planes of TSS- 2 sample are parallel to the sliding direction of balls, the shear stresses induce the dislocation walls along the basal planes and after unloading the dislocation walls disappear following the reversible elastic deformation. Therefore, the wear rate of TSS- 2 sample could be effectively decreased based on the elastic recovery and energy dissipative mechanism inside the material.

In Table 3, the wear rates of SUS304 balls are given for the different surface orientations. The wear rates of balls increase from $12.67 \times 10^{-5}$ to $272.56 \times$ $10^{-5} \mathrm{~mm}^{3} /(\mathrm{N} \cdot \mathrm{m})$ with increasing loads of 1,5 , and $9 \mathrm{~N}$ for TTS samples. Similarly, those of balls counterfacing TSS-1 samples show a continuous increase from $2.97 \times 10^{-5}$ to $15.81 \times 10^{-5} \mathrm{~mm}^{3} /(\mathrm{N} \cdot \mathrm{m})$. This is ascribed to the larger contact surface area and the higher quantity of debris formed which increase the third body abrasion. However, the wear rates of SUS304 balls against TSS-2 samples show a reverse tendency, decreasing from $3.13 \times 10^{-5}$ to $1.51 \times 10^{-5} \mathrm{~mm}^{3} /(\mathrm{N} \cdot \mathrm{m})$ and then $1.77 \times 10^{-5} \mathrm{~mm}^{3} /(\mathrm{N} \cdot \mathrm{m})$ with increasing load. This result might be associated with the less debris on the worn surface of TSS-2 samples with the increment of load, confirmed by Fig. 3 .

\section{3 Worn mechanisms}

Figure 3 shows the worn surface of textured $\mathrm{Ti}_{3} \mathrm{AlC}_{2}$ under the loads of 1 and $9 \mathrm{~N}$ along the different texture directions. The correspondent worn surfaces of SUS304 balls were also observed, as shown in Fig. 4. It is seen that under the load of $1 \mathrm{~N}$ on the worn surface of TTS sample some plates are kept to support the sliding balls, effectively enhancing the wear resistance (Fig. 3(a)). Some debris forms and deposits in pits. However, under the load of $9 \mathrm{~N}$, the damage becomes extensive and only debris could be found on the wear track (Fig. 3(b)), which indicates that the basal planes have been easily debonded by shearing. That is why the wear rate of TTS sample is so high under $9 \mathrm{~N}$, as indicated in Table 2. Similarly, the counter sliding balls present a clear shear wear induced damage by the third body under $9 \mathrm{~N}$ (Fig. 4(b)), which is more intense in comparison with the balls tested under $1 \mathrm{~N}$ (Fig. 4(a)).

On the worn surface of TSS-1 sample, though the spalling-off of grains caused by the shear stresses becomes more severe for $9 \mathrm{~N}$ than for $1 \mathrm{~N}$ and there are a plenty of debris filling in the pit regions (Figs. 3(c) and 3(d)), the protuberant plates could still
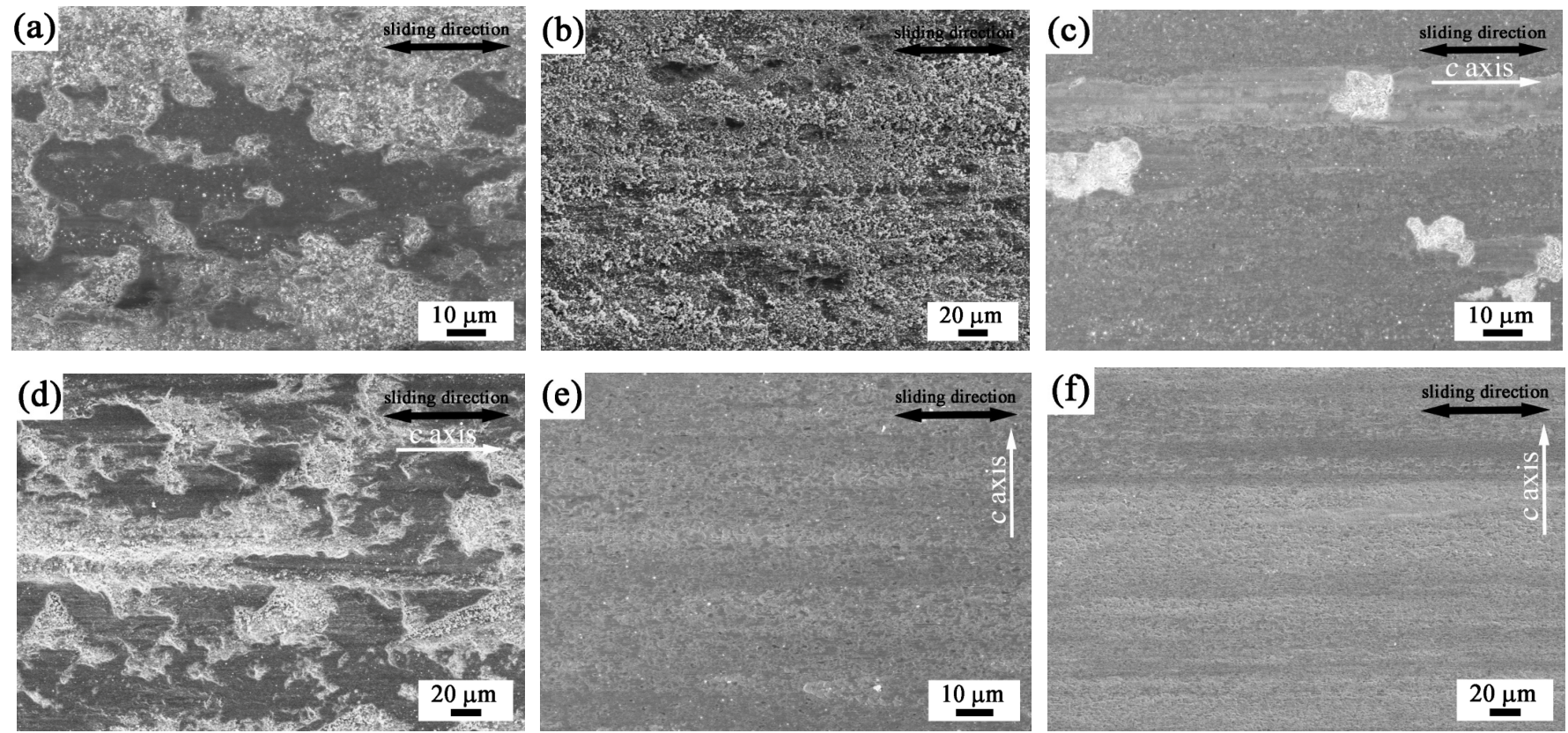

Fig. 3 SEM micrographs of worn surface of tailored $\mathrm{Ti}_{3} \mathrm{AlC}_{2}$ ceramic under the loads of 1 and $9 \mathrm{~N}$ along the different texture directions: (a, b) TTS sample, (c, d) TSS-1 sample, and (e, f) TSS-2 sample. 

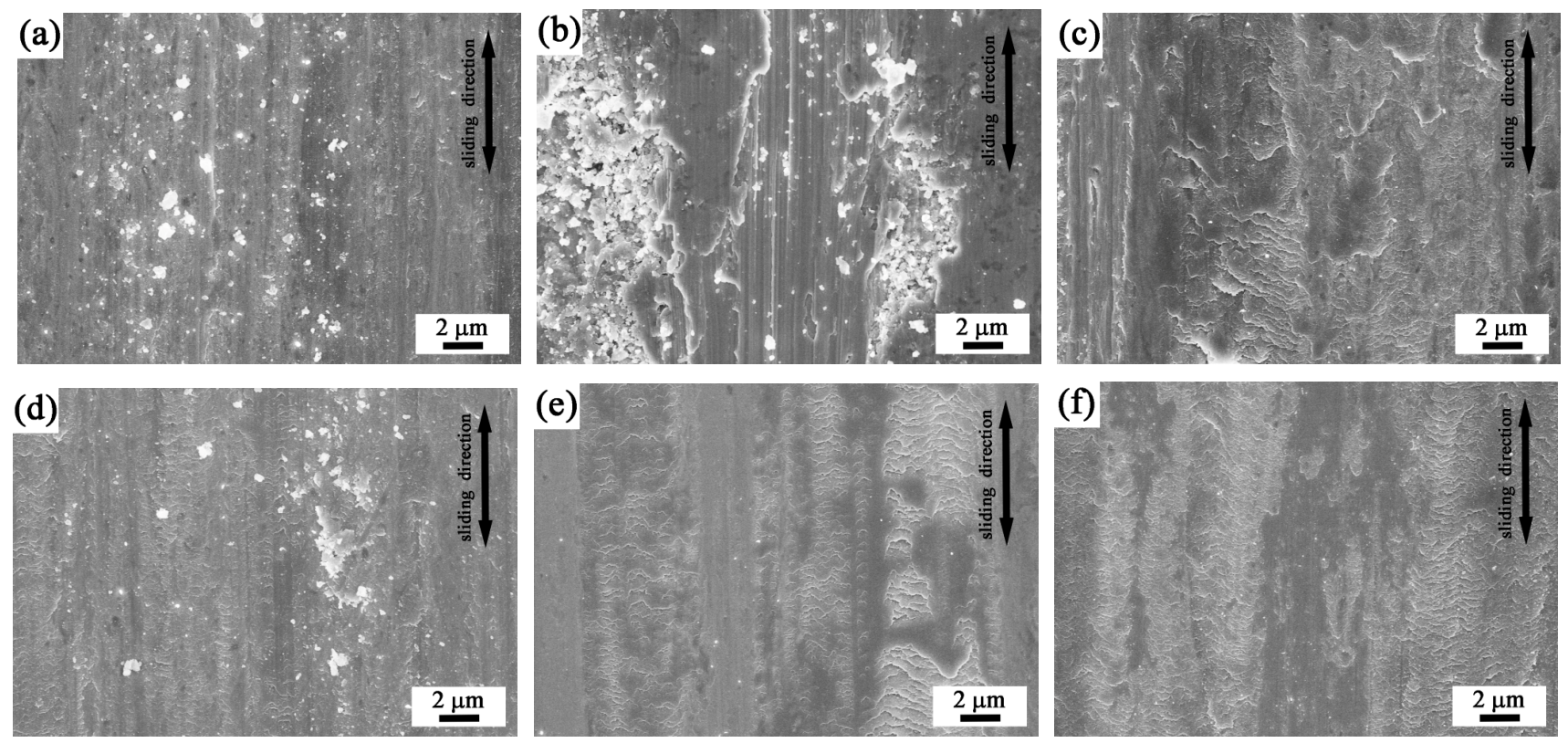

Fig. 4 SEM micrographs of worn surface of SUS304 balls tested under the loads of 1 and 9 N: (a, b) against TTS sample, (c, d) against TSS-1 sample, and (e, f) against TSS-2 sample.

effectively endure the rubbing of balls. So, the wear rate of TSS-1 sample shows an inverse tendency with increasing load. Reversely, the wear rates of counterpair balls increase with the increment of load owing to the worse third body abrasion, as shown in Figs. 4(c) and 4(d). When tested at $1 \mathrm{~N}$, no debris can be found on the worn surface of balls and a layer of compacted debris is formed. Under the load of $9 \mathrm{~N}$, the loose debris adheres onto the worn surface of balls, accelerating the wear loss of balls. Interestingly, on the worn surface of TSS-2 sample (Figs. 3(e) and 3(f)), even under the highest load of $9 \mathrm{~N}$, there are no formed spalling-off regions and only tiny debris can be observed. It is why the wear rate of TSS-2 sample presents the decreasing value with increasing load. Similarly, on the worn surface of SUS304 balls (Figs. 4(e) and 4(f)), only compacted fish-scaled debris can be observed along the sliding direction. Due to the lack of the third body, the wear rates of balls also show the general decreasing tendency (Table 3 ).

Figure 5 shows the SEM micrographs of debris collected on the worn surface of $\mathrm{Ti}_{3} \mathrm{AlC}_{2}$ samples tested along different texture directions, as well as their EDS results. It is clearly seen that the debris consists of nano sized particles (Figs. 5(a)-5(c)), which means that the reciprocating wear process has effectively crushed the surface grains. The debris serves as the third body to strengthen the wear effect. In addition, it is detected that $\mathrm{Ti}, \mathrm{Al}, \mathrm{Cr}, \mathrm{Fe}, \mathrm{C}$, and $\mathrm{O}$ elements exist in the debris. Wu et al. [35] have determined that the
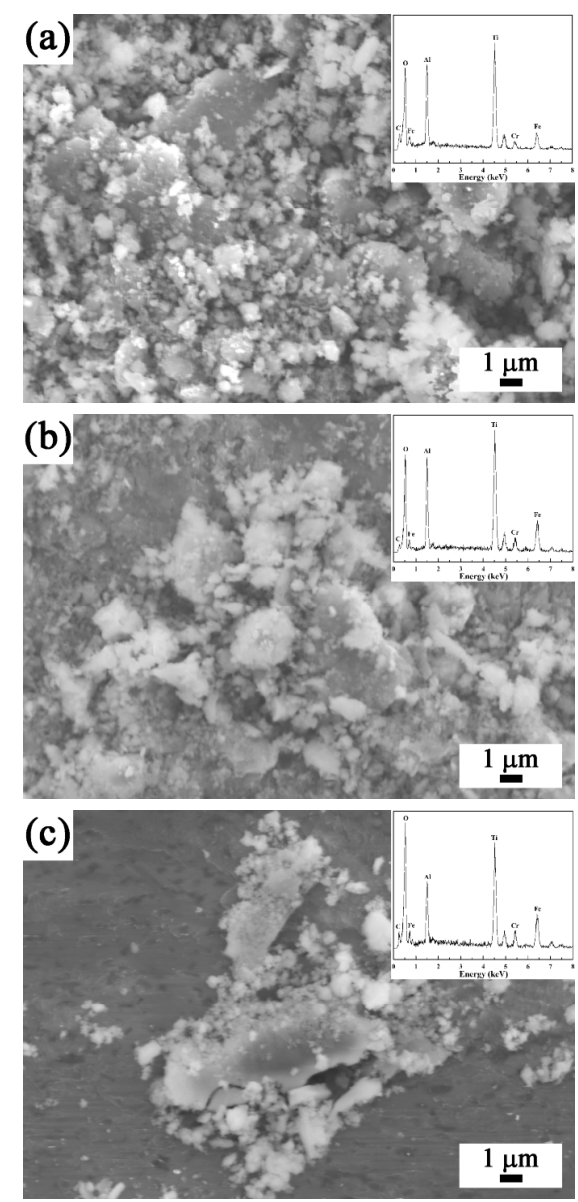

Fig. 5 SEM micrographs and EDS analysis of debris on the worn surface of tailored $\mathrm{Ti}_{3} \mathrm{AlC}_{2}$ ceramic tested under the load of $5 \mathrm{~N}$ : (a) TTS sample, (b) TSS-1 sample, and (c) TSS-2 sample. 
dry sliding process in air could induce the oxidation of debris under the contact region of countercouples of $\mathrm{Ti}_{3} \mathrm{AlC}_{2} / \mathrm{AISI}-52100$ bearing steel [35]. Possibly, $\mathrm{TiO}_{2}$, $\mathrm{Al}_{2} \mathrm{O}_{3}$, and $\mathrm{Fe}_{2} \mathrm{O}_{3}$, etc., have been formed during the sliding, which contribute to lowering the coefficient of friction [36].

Figure 6 indicates the high magnification images of worn regions of tailored $\mathrm{Ti}_{3} \mathrm{AlC}_{2}$ after ultrasonic cleaning. On the TTS, the material remove mechanisms are determined as grains' delamination and peeling-off at the positions of basal planes (Fig. 6(a)). The sliding balls have scratched the texture grains layer by layer. For TSS-1 sample, the damage mechanisms are represented by the delamination and pulling-out of grains by scratching (Fig. 6(b)). Interestingly, for TSS-2 sample, only plowing tracks can be observed and no crushed grains are found on the worn surface (Fig. 6(c)).

In order to understand the mechanical responses of texture microstructure of textured $\mathrm{Ti}_{3} \mathrm{AlC}_{2}$ and to explain the worn mechanisms, the Vickers indents
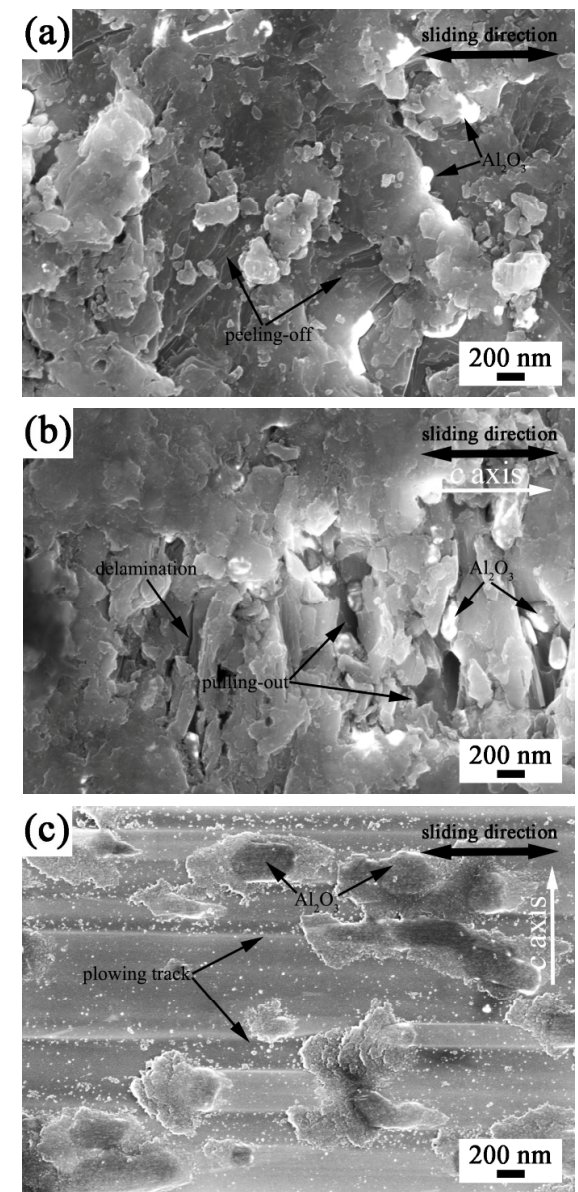

Fig. 6 Wear damages on different texture surfaces of tailored $\mathrm{Ti}_{3} \mathrm{AlC}_{2}$ ceramic when tested at $1 \mathrm{~N}$ : (a) TTS, (b) TSS-1, and (c) TSS-2. (load of $50 \mathrm{~N}$ ) on the worn surface were examined as shown in Fig. 7. Clearly, it is seen that the morphologies of indents are different depending on the textured surface. On the TTS, the indent is a square (symmetric) and the materials are pushed out around the indented area by the shear stresses (Fig. 7(a)), indicating the isotropic (on the TTS plane) mechanical response. However, on the worn surface of TSS-1 sample, the indent shows rhombohedral shape (asymmetrical), reflecting its anisotropic mechanical response. Along the sliding direction of balls, the materials are easy to be delaminated, crushed, and pushed out, exhibiting the irreversible plastic deformation (Fig. 7(b)). Reversely, on the worn surface of TSS-2 sample, the rhombus indent shows that no crushed grains exist at the corners along the sliding direction and the diagonal line is shorter, proving the elastic recovery after the release of stresses (Fig. 7(c)). It is confirmed that the soft-hard combination with typical nanolaminar structure contributes to the excellent elastic mechanical
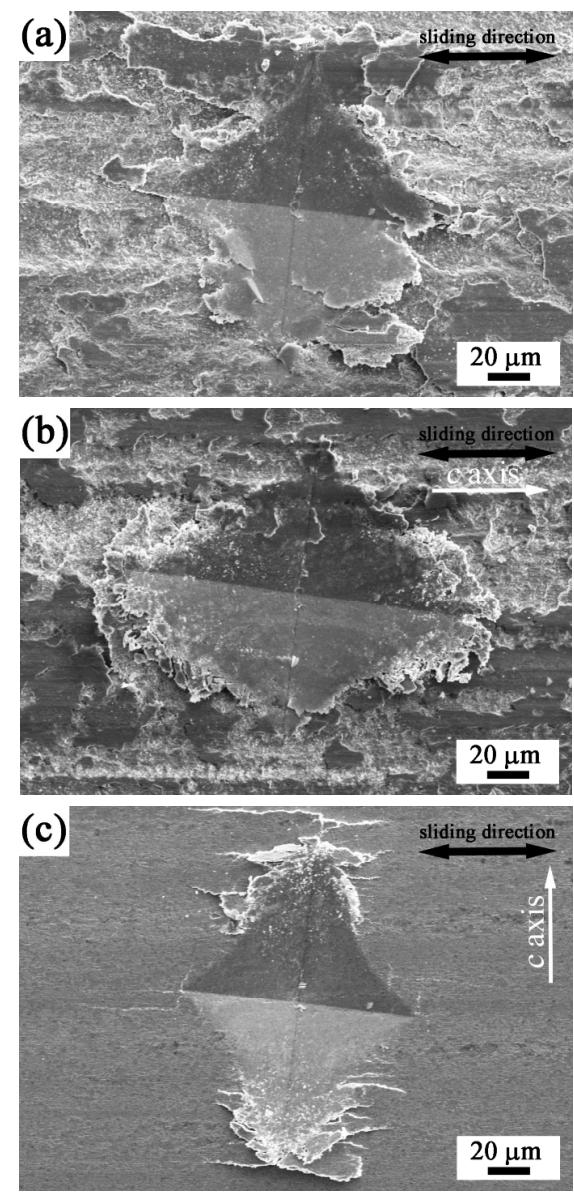

Fig. 7 Vickers indents induced by a load of $50 \mathrm{~N}$ on the worn surface of tailored $\mathrm{Ti}_{3} \mathrm{AlC}_{2}$ ceramic tested under $5 \mathrm{~N}$ : (a) TTS sample, (b) TSS-1 sample, and (c) TSS-2 sample. 
reversibility. These experimental results strongly support that the preferential texture microstructure in $\mathrm{Ti}_{3} \mathrm{AlC}_{2}$ strongly affects its wear resistance.

\section{Conclusions}

Tribological behaviors of tailored $\mathrm{Ti}_{3} \mathrm{AlC}_{2}$ ceramic were investigated by using the reciprocating mode against SUS304 balls under the loads of 1, 5, and $9 \mathrm{~N}$. The tribological properties (mean coefficient of friction and wear rate) were strongly affected by the crystallographic texturing. On the TTS ((000l) plane), the mean coefficient of friction showed the lowest value compared to those of TSS-1 and TSS-2 samples under the same load. On the TSS-2, the lowest wear rate of $1.51 \times 10^{-3} \mathrm{~mm}^{3} /(\mathrm{N} \cdot \mathrm{m})$ was achieved when tested under the load of $9 \mathrm{~N}$, and interestingly the wear rate showed a decreased value with the increased load. The worn mechanisms on the TTS and TSS-1 were confirmed as delamination, grain crushing, and grain pulling-out, and that of TSS-2 sample was mainly attributed to the plowing effect by scratching.

\section{Acknowledgements}

This work is supported by "ChuYing" Program of Southwest Jiaotong University and Thousand Talents Program of Sichuan Province. Also, we thank for the supports of National Natural Science Foundation of China (Nos. U1232136 and 91226202), Grant-in-Aid for Scientific Research B (No. 23350104) from Japan Society for the Promotion Science, the Fundamental Research Program of Korean Institute of Materials Science (KIMS), and UK EPSRC Material Systems for Extreme Environments Programme Grant (EP/K008749/1, XMat).

\section{References}

[1] Barsoum M, El-Raghy T. The MAX phases: Unique new carbide and nitride materials. Am Sci 2001, 89: 334-343.

[2] Barsoum M, Radovic M. Mechanical properties of the MAX phases. Encyclopedia Mater: Sci Tech 2004: 1-16.

[3] Wang $\mathrm{XH}$, Zhou YC. Layered machinable and electrically conductive $\mathrm{Ti}_{2} \mathrm{AlC}$ and $\mathrm{Ti}_{3} \mathrm{AlC}_{2}$ ceramics: A review. J Mater Sci Technol 2010, 26: 385-416.

[4] Sun ZM. Progress in research and development on MAX phases: A family of layered ternary compounds. Int Mater Rev 2011, 56: 143-166.

[5] Eklund P, Beckers M, Jansson U, et al. The $\mathrm{M}_{n+1} \mathrm{AX}_{n}$ phases: Materials science and thin-film processing. Thin Solid Films 2010, 518: 1851-1878.

[6] Zhang J, Liu B, Wang JY, et al. Low-temperature instability of $\mathrm{Ti}_{2} \mathrm{SnC}$ : A combined transmission electron microscopy, differential scanning calorimetry, and X-ray diffraction investigations. J Mater Res 2009, 24: 39-49.

[7] Lin Z, Zhuo M, Zhou Y, et al. Microstructure and theoretical bulk modulus of layered ternary tantalum aluminum carbides. $J$ Am Ceram Soc 2006, 89: 3765-3769.

[8] Zheng L, Wang J, Lu X, et al. $\left(\mathrm{Ti}_{0.5} \mathrm{Nb}_{0.5}\right)_{5} \mathrm{AlC}_{4}$ : A new-layered compound belonging to MAX phases. $J \mathrm{Am}$ Ceram Soc 2010, 93: 3068-3071.

[9] $\mathrm{Hu} \mathrm{C}$, Lai C-C, Tao Q, et al. $\mathrm{Mo}_{2} \mathrm{Ga}_{2} \mathrm{C}$ : A new ternary nanolaminated carbide. Chem Commun 2015, 51: 6560-6563.

[10] Wan D, Zhou Y, Hu C, et al. Improved strength-impairing contact damage resistance of $\mathrm{Ti}_{3} \mathrm{Si}(\mathrm{Al}) \mathrm{C}_{2} / \mathrm{SiC}$ composites. J Eur Ceram Soc 2007, 27: 2069-2076.

[11] Lee DB, Park SW. High-temperature oxidation of $\mathrm{Ti}_{3} \mathrm{AlC}_{2}$ between 1173 and $1473 \mathrm{~K}$ in air. Mat Sci Eng A 2006, 434: $147-154$.

[12] Zhu J, Ye L, He L. Microstructure and mechanical properties of in situ synthesized $\mathrm{Ti}_{2} \mathrm{AlC} / \mathrm{Al}_{2} \mathrm{O}_{3}$ composites. Mat Sci Eng A 2012, 547: 6-11.

[13] Duan X, Shen L, Jia D, et al. Synthesis of high-purity, isotropic or textured $\mathrm{Cr}_{2} \mathrm{AlC}$ bulk ceramics by spark plasma sintering of pressure-less sintered powders. $J$ Eur Ceram Soc 2015, 35: 1393-1400.

[14] Heinzel A, Müller G, Weisenburger A. Compatibility of $\mathrm{Ti}_{3} \mathrm{SiC}_{2}$ with liquid $\mathrm{Pb}$ and $\mathrm{PbBi}$ containing oxygen. J Nucl Mater 2009, 392: 255-258.

[15] Tallman DJ, Hoffman EN, Caspi EN, et al. Effect of neutron irradiation on select MAX phases. Acta Mater 2015, 85: 132-143.

[16] Nappé JC, Monnet I, Grosseau P, et al. Structural changes induced by heavy ion irradiation in titanium silicon carbide. J Nucl Mater 2011, 409: 53-61.

[17] Gupta S, Filimonov D, Zaitsev V, et al. Ambient and $550{ }^{\circ} \mathrm{C}$ tribological behavior of select MAX phases against Ni-based superalloys. Wear 2008, 264: 270-278.

[18] Gupta S, Filimonov D, Palanisamy T, et al. Tribological behavior of select MAX phases against $\mathrm{Al}_{2} \mathrm{O}_{3}$ at elevated temperatures. Wear 2008, 265: 560-565.

[19] Ren S, Lu J, Jia Q, et al. Tribochemistry of $\mathrm{Ti}_{3} \mathrm{SiC}_{2} / \mathrm{Si}_{3} \mathrm{~N}_{4}$ tribopair in ethanol. Tribol Int 2014, 74: 174-180.

[20] Ren S, Meng J, Wang J, et al. Tribo-corrosion behaviors of $\mathrm{Ti}_{3} \mathrm{SiC}_{2} / \mathrm{Si}_{3} \mathrm{~N}_{4}$ tribo-pair in hydrochloric acid and sodium hydroxide solutions. Wear 2012, 274-275: 8-14.

[21] Zhu Y, Zhou A, Ji Y, et al. Tribological properties of $\mathrm{Ti}_{3} \mathrm{SiC}_{2}$ coupled with different counterfaces. Ceram Int 2015, 41: 6950-6955.

[22] Wan DT, Hu CF, Bao YW, et al. Effect of SiC particles on the friction and wear behavior of $\mathrm{Ti}_{3} \mathrm{Si}(\mathrm{Al}) \mathrm{C}_{2}$-based composites. Wear 2007, 262: 826-832.

[23] Hu C, Zhou Y, Bao Y, et al. Tribological properties of polycrystalline $\mathrm{Ti}_{3} \mathrm{SiC}_{2}$ and $\mathrm{Al}_{2} \mathrm{O}_{3}$-reinforced $\mathrm{Ti}_{3} \mathrm{SiC}_{2}$ composites. J Am Ceram Soc 2006, 89: 3456-3461. 
[24] Hu C, Sakka Y, Tanaka H, et al. Fabrication of textured $\mathrm{Nb}_{4} \mathrm{AlC}_{3}$ ceramic by slip casting in a strong magnetic field and spark plasma sintering. $J$ Am Ceram Soc 2011, 94: 410-415.

[25] Hu C, Sakka Y, Nishimura T, et al. Physical and mechanical properties of highly textured polycrystalline $\mathrm{Nb}_{4} \mathrm{AlC}_{3}$ ceramic. Sci Technol Adv Mat 2011, 12: 44603-44608.

[26] $\mathrm{Hu} \mathrm{C}$, Sakka Y, Grasso S, et al. Tailoring $\mathrm{Ti}_{3} \mathrm{SiC}_{2}$ ceramic via a strong magnetic field alignment method followed by spark plasma sintering. J Am Ceram Soc 2011, 94: $742-748$.

[27] Zhang $\mathrm{HB}$, $\mathrm{Hu} \mathrm{CF}$, Sato $\mathrm{K}$, et al. Tailoring $\mathrm{Ti}_{3} \mathrm{AlC}_{2}$ ceramic with high anisotropic physical and mechanical properties. J Eur Ceram Soc 2015, 35: 393-397.

[28] Hu C, Sakka Y, Grasso S, et al. Shell-like nanolayered Nb4AlC3 ceramic with high strength and toughness. Scripta Mater 2011, 64: 765-768.

[29] Huang Z, Zhai H, Guan M, et al. Oxide-film-dependent tribological behaviors of $\mathrm{Ti}_{3} \mathrm{SiC}_{2}$. Wear 2007, 262: 1079-1085.

[30] Ma J, Hao J, Fu L, et al. Intrinsic self-lubricity of layered $\mathrm{Ti}_{3} \mathrm{AlC}_{2}$ under certain vacuum environment. Wear 2013, 297: 824-828.

[31] Zhou AG, Barsoum MW, Basu S, et al. Incipient and regular kink bands in fully dense and 10 vol.\% porous $\mathrm{Ti}_{2} \mathrm{AlC}$. Acta Mater 2006, 54: 1631-1639.
[32] Gupta S, Barsoum MW. On the tribology of the MAX phases and their composites during dry sliding: A review. Wear 2011, 271: 1878-1894.

[33] Barsoum MW, Zhen T, Kalidindi SR, et al. Fully reversible, dislocation-based compressive deformation of $\mathrm{Ti}_{3} \mathrm{SiC}_{2}$ to $1 \mathrm{GPa}$. Nat Mater 2003, 2: 107-111.

[34] Jones NG, Humphrey C, Connor LD, et al. On the relevance of kinking to reversible hysteresis in MAX phases. Acta Mater 2014, 69: 149-161.

[35] Wu L, Chen J, Liu M, et al. Reciprocating friction and wear behavior of $\mathrm{Ti}_{3} \mathrm{AlC}_{2}$ and $\mathrm{Ti}_{3} \mathrm{AlC}_{2} / \mathrm{Al}_{2} \mathrm{O}_{3}$ composites against AISI52100 bearing steel. Wear 2009, 266: 158-166.

[36] Lindquist $\mathrm{M}$, Wilhelmsson $\mathrm{O}$, Jansson U, et al. Tribofilm formation from $\mathrm{TiC}$ and nanocomposite TiAlC coatings, studied with focused ion beam and transmission electron microscopy. Wear 2009, 266: 988-994.

Open Access The articles published in this journal are distributed under the terms of the Creative Commons Attribution 4.0 International License (http://creativecommons. org/licenses/by/4.0/), which permits unrestricted use, distribution, and reproduction in any medium, provided you give appropriate credit to the original author(s) and the source, provide a link to the Creative Commons license, and indicate if changes were made. 